\title{
A CRÍTICA DE ARTE NOS JORNAIS DE 1955 A 2005: O CASO CARIOCA
}

Bianca Andrade Tinoco

Pontifícia Universidade Católica do Rio de Janeiro (PUC-Rio)

\section{A crítica de arte nos jornais de 1955 a 2005 - o caso carioca}

A crítica de artes visuais publicada em jornais de grande circulação é atualmente um gênero em extinção, tendência que pode ser constatada em todo o Brasil. A situação é mais aguda no Rio de Janeiro, ex-capital federal e até hoje um dos principais centros de ressonância artística do país. Apesar das centenas de exposições inauguradas anualmente na cidade, apenas um jornal carioca contava, em 2006, com um crítico em sua folha de pagamento - o filósofo Luiz Camillo Osório, colaborador de O Globo.

A exígua freqüência da crítica em jornais, hoje, torna-se mais significativa quando lembramos que, em 1957, o Jornal do Brasil publicava diariamente textos do crítico Mário Pedrosa em uma coluna no primeiro caderno, o mesmo dedicado às principais notícias do país e do mundo. Em 50 anos, a crítica de arte no Brasil passou de uma esfera ampla, com divulgação diária nos meios de comunicação, para outra quase totalmente restrita ao debate acadêmico, exercida por meio de artigos, dissertações, teses e seminários.

Muitos são os fatores que contribuíram para esse esgarçamento da relação crítica-jornais, decorrentes tanto de mudanças na produção artística quanto do desenvolvimento econômico e tecnológico dos meios de comunicação no país. Nos últimos 50 anos, por exemplo, instalou-se mundialmente uma crise da crítica de arte, com a mudança de paradigmas na passagem da arte moderna para a contemporânea. Até a década de 50, no Brasil, era o discurso do crítico, aliado aos manifestos dos artistas, que desvendava para um público habituado ao naturalismo o sentido de obras que, pela primeira vez na história, se afirmavam como totalmente dissociadas da representação. Até aquele momento, o crítico era a autoridade que definia o que era ou não arte. Tanto o neoconcretismo quanto a arte conceitual, entretanto, tiraram de cena um elemento fundamental para a crítica moderna: a obra física, o objeto de arte a ser avaliado. Ao se voltarem para o conceito e para a desmaterialização da arte, o não-objeto, tais artistas deslocaram o debate crítico. Com a ascensão da arte contemporânea, as certezas modernas ficaram em suspenso. Os 
métodos e procedimentos de análise modernos entraram em choque com a produção artística contemporânea e não encontraram meios para abordá-la.

Para completar o quadro de crise, os artistas contemporâneos rejeitavam o fazer crítico por associá-lo a um mercado de arte em crescimento no Brasil dos anos 70 e ávido por absorver (e tirar o impacto) da produção do período. Tal choque foi temporário, mas se abrandou apenas depois que os críticos reinterpretaram sua identidade e encontraram lugar para exercer seu trabalho e estabelecer conexões com a arte de seu tempo.

\section{A crítica em jornais antes de 1955}

A publicação de crítica de arte em jornais começou a se consolidar na imprensa internacional a partir de iniciativas como a revista diária The Spectator, fundada em 1711. Com poucas exceções, a crítica de arte foi muito próxima à literatura até o início do século XX, sendo exercida quase exclusivamente por escritores, tais como o filósofo iluminista Denis Diderot, no século XVIII, e o poeta Charles Baudelaire, no XIX.

Poeta genial e intelectual controverso, Baudelaire consagrou-se primeiramente no circuito cultural de Paris como crítico de arte, a partir de seu artigo "Salão de 1845" publicado em jornais da época. Paralelamente à sua atividade poética, desenvolveu uma obra crítica coerente com os critérios que estabeleceu - alguns dos quais viriam a se tornar leis para toda a crítica posterior. $O$ texto dele era informal, sempre em primeira pessoa. Mas, no momento das conclusões, revelava-se implacável na avaliação de artistas e obras. No sugestivo texto "Para que serve a crítica", parte do artigo "Salão de 1846", Baudelaire revela as condições que considera indispensáveis no texto crítico: "para ser correta, ou seja, para ter sua razão de ser, a crítica deve ser parcial, apaixonada, política - isto é, concebida de um ponto de vista exclusivo, mas que descortina o máximo de horizontes."1

Influenciados pelo modelo francês, os periódicos brasileiros do século XIX começaram a dedicar parte de seu noticiário a questões culturais. No Rio de Janeiro, o precursor foi o jornalista Luís Gonzaga Duque Estrada (1863-1911), considerado o primeiro crítico de arte sistemático do país. Atuante na imprensa carioca de 1886 a 1891, Gonzaga

1 Baudelaire, Charles. "Para que serve a crítica", in Baudelaire, Charles. A modernidade de Baudelaire, p. 20. 
Duque julgava as obras a partir da experiência frente a elas. O crítico impôs para si a missão de incentivar os artistas a se afastarem dos modelos da Academia Imperial de Belas Artes, os quais considerava ultrapassados. Gonzaga Duque buscou a formação de uma cultura estética que contivesse "uma reflexão sobre as condições singulares do país, mas afinada com uma cultura e uma tradição universais" 2 .

\section{Nos jornais, o reinado da objetividade}

Os grandes jornais brasileiros consolidaram na segunda metade do século XX um modelo industrial de produção. Por meio de reformas gráficas e de estilo, absorveram a modernização ocorrida em similares europeus e da América do Norte. Os artigos de influência literária foram substituídos pelas reportagens objetivas. Os textos opinativos, como as colunas e as críticas, paulatinamente foram segregados.

A década de 1950 foi de grande reconhecimento e euforia para o jornalismo cultural. A diversão e as artes rompiam o recesso doméstico para se tornarem bens de consumo: na década de 40, são fundados o Museu de Arte de São Paulo (1947), o Teatro Brasileiro de Comédia (1948), a companhia de cinema Vera Cruz (1949), a TV Tupi (1950). Em 1951, é realizada a $1^{\text {a }}$ Bienal de São Paulo. Um mesmo jornal, e por vezes até o mesmo crítico, publicava três, quatro avaliações de uma determinada atração, em diferentes momentos da temporada. Com a reforma gráfica e editorial no fim dos anos 50, o Jornal do Brasil foi pioneiro ao criar o Suplemento Dominical do Jornal do Brasil (SDJB), em 1956. Quatro anos depois, lançou o Caderno B, primeiro suplemento cultural diário do país.

Nos anos 60, entretanto, o mercado jornalístico sofreu um golpe considerável: um aumento de $3.294 \%$ no preço do papel para a impressão dos jornais, de fevereiro de 1958 a julho de 19633. Com a crise, os empresários diminuíram o espaço para textos e cortaram o número de funcionários. Durante o regime militar, de 1964 a 1984, a censura foi outro fator limitador do jornalismo cultural, bloqueando a liberdade de expressão. Por outro lado, estimulou indiretamente publicações de contestação tais como O Pasquim e Opinião.

2 Lins, Vera. “Gonzaga Duque: crítica e utopia na virada do século”, p. 13.

3 Sodré, Nelson Werneck. História da imprensa no Brasil., p. 411. 
O jornalismo de serviço surgiu nos anos 60 com o objetivo de informar superficialmente o leitor sobre as novidades de consumo, inclusive as relacionadas a cultura. Graças ao gênero, consagrado na década de 80 , a crítica de artes visuais perdeu espaço e passou a se referir quase unicamente às exposições locais.

$\mathrm{Na}$ década de 90, o padrão de notícias curtas e atração visual popularizado pela internet e pelos canais de telejornalismo 24 horas foi transposto para os jornais, reduzindo-se ainda mais o espaço da crítica. Tomando-se como exemplo $O$ Globo, as críticas de cinema e música são publicadas semanalmente, com cotações e comentários para diversos lançamentos. A cada semana, são impressas duas ou três críticas de teatro. Espetáculos de dança e exposições ganham críticas em média quatro vezes por mês. Dessa maneira, os cadernos culturais vêm perdendo a capacidade de provocar a sensibilidade do leitor.

\section{Crítica em quatro tempos}

Para nos aprofundarmos nos percalços vivenciados pelos críticos na segunda metade do século $\mathrm{XX}$, abordamos a seguir a produção de quatro nomes preponderantes no diálogo artístico, de acordo com as décadas nas quais exerceram maior influência: Mário Pedrosa (1900-1981), nos anos 50; Ferreira Gullar (1930), nos 60; Ronaldo Brito (1949), na década de 70; e Frederico Morais (1936); na de 80. Tal divisão, realizada com fins didáticos, nos permite visualizar as condições de possibilidade da crítica em jornais em cada período.

Pedrosa consagrou-se, em quase 50 anos de produção, como o mais influente crítico brasileiro da segunda metade do século XX. Vicepresidente da Associação Internacional de Críticos de Arte de 1957 a 1970, diretor geral da Bienal de São Paulo de 1961, diretor do Museu de Arte Moderna de São Paulo de 1961 a 1963, Pedrosa fez dos jornais diários seu principal meio para a exposição de idéias e críticas. Foi colaborador de mais de uma dezena deles, entre os quais Correio da Manhã (1943-1951 e 196368), Tribuna da Imprensa (1950-1954), Jornal do Brasil (1957-1961) e Folha de S. Paulo (1978).

Em 1950, Mário Pedrosa já carregava a fama de "arauto das vanguardas artísticas", como se definia. Defensor da nascente arte abstrata geométrica no Brasil, ele destacava questões delicadas da produção ainda de cunho modernista, presa à figuração, às lições do cubismo e do expressionismo e a uma temática nacionalista. Para o crítico, a abstração 
geométrica era enfim um fenômeno de caráter brasileiro, e não uma imitação de padrões da arte mundial, pois descenderia da maneira racional com a qual a arquitetura e o artesanato brasileiros trabalharam a forma ao longo da história. Não à toa, Pedrosa tornou-se mentor dos grupos Frente e Ruptura, vanguardas concretas do Rio de Janeiro e de São Paulo.

$\mathrm{Na}$ seção de arte do Correio da Manhã, Pedrosa usava uma linguagem simples, falava diretamente ao leitor e não exibia os traços literários. Sobressaíam em seus textos a erudição, o rigor interpretativo e a sutileza de sua percepção formal. Pedrosa defendia que o artista moderno tinha a missão social de emancipar o espectador de recepção contemplativa da obra, por meio da formação de uma nova sensibilidade. Adotou o mesmo estilo no Jornal do Brasil, para o qual escreveu diariamente de 1957 a 1961, na coluna Artes Visuais. Para Otília Arantes, Mário Pedrosa foi “o primeiro em nossa tradição crítica a ajustar com rara felicidade a elaboração teórica aos requisitos igualmente complexos do ato crítico de primeira mão, elevando ao mesmo tempo a crítica exercida nas páginas da imprensa diária ao patamar mais exigente da norma culta internacional." 4

Com sua crítica combativa, Mário Pedrosa redimensionou a reflexão sobre arte no país. Criou no Brasil em 1966 o conceito de arte pósmoderna, quase uma década antes que ele entrasse em discussão no meio internacional, e cunhou também a visão da "arte como exercício experimental da liberdade", em 1970. Para Ronaldo Brito, "não é exagero dizer que Mário Pedrosa fez mais do que influenciar os agentes da arte brasileira - ele impregnou o circuito com suas idéias e suas posições diante do trabalho de arte". ${ }^{5}$

Pedrosa foi uma das principais referências para outro crítico que também trabalhou no $J B$ nos anos 50: o poeta Ferreira Gullar. A atuação dele como crítico regular em jornais foi relativamente curta, de 1956 a 1961. Entretanto, ao mesmo tempo artista neoconcreto e crítico, Gullar inaugurou um enfoque híbrido, entre a fala artística e a avaliação de trabalhos, que forneceu bases valiosas para o desenvolvimento da arte neoconcreta.

Ferreira Gullar foi responsável desde 1956 pela página de Artes Plásticas do Suplemento Dominical do Jornal do Brasil. Nela, tinha liberdade para tratar dos assuntos que julgasse interessantes - de exposições no Rio e em

\footnotetext{
4 PEDROSA, Mário. Forma e percepção estética - textos escolbidos II, pp. 10 e 11.

5 BRITO, Ronaldo. Experiência crítica., p. 48.
} 
São Paulo a temas controversos da arte mundial. Também em 1956, deu vazão à veia de poeta concreto participando da I Exposição Nacional de Arte Concreta, no Museu de Arte Moderna de São Paulo, em 1956.

Em nome do Grupo Frente e em oposição ao Ruptura, Ferreira Gullar escreveu em 1957 o artigo crítico "Poesia concreta: experiência fenomenológica", o qual provocou o afastamento dos grupos e estabeleceu as bases do movimento neoconcreto. Mergulhando nas premissas de sensorialidade da obra e participação do espectador, produziu nos anos seguintes obras como o "Poema-objeto" e o "Poema enterrado", na fronteira da literatura com a obra de arte. Tomando como exemplo seu trabalho e também os de artistas como Hélio Oiticica e Lygia Clark, Gullar foi o autor em 1959 do "Manifesto Neoconcreto", publicado em 1959 no SDJB durante a I Exposição Neoconcreta no MAM/RJ. Assinado pelos demais integrantes do movimento, o texto reitera a contrariedade do grupo carioca à extrema racionalidade dos concretistas paulistanos e afirma que o neoconcreto nasce "de uma necessidade de exprimir a complexa realidade do homem moderno dentro da linguagem estrutural da nova plástica"6. Do mesmo ano, 1959, é o "Diálogo sobre o Não-Objeto", seguido em dezembro de 1960 pela "Teoria do Não-Objeto", também publicada no SDJB. Ambos foram primordiais para a consolidação das propostas do neoconcretismo.

As pesquisas de Gullar no campo da arte neoconcreta - e, coincidentemente, sua atuação como crítico no Jornal do Brasil - foram até 1961. Gullar mudou-se para Brasília, a convite de Jânio Quadros, e arrependeu-se repentinamente das experimentações feitas ao lado dos neoconcretos - segundo ele, por entrever nelas o fim da arte. Posteriormente Gullar colaborou com O Estado de S. Paulo e o Pasquim, nos anos 60 e 70, e depois com a revista Veja e o suplemento Folhetim, mas sua produção crítica mais importante é justamente esta renegada por ele, essencial para que se compreendam hoje os fundamentos do neoconcretismo, o estopim de um dos momentos mais férteis da arte brasileira.

Um dos críticos de arte mais respeitados em atividade no país, Ronaldo Brito começou na profissão na equipe do jornal alternativo carioca Opinião, de 1972 a 1977. Foi redator e depois sub-editor da seção

6 Gullar, Ferreira. "Manifesto da arte neoconcreta".

In http://portalliteral.terra.com.br/ferreira_gullar/porelemesmo/index.shtml?porelemesmo. 
“Tendências e Cultura”, que trazia nas páginas finais do jornal indicações de cinema, teatro, livros, discos e programas de TV. O texto dele no jornal, fosse avaliando livros de arte, trabalhos, salões ou a política cultural do período, buscava ser claro, mas também poético e reflexivo. Influenciado pela crítica européia e norte-americana do período, Brito não tratava seu interlocutor com intimidade nem o entendia como leigo em arte, mas como alguém que acompanha as exposições e novidades em arte. A arte brasileira era abordada por ele dentro de um contexto mundial no qual nacionalidades eram menos importantes do que as poéticas desenvolvidas por cada artista.

Tendo como principal foco de pesquisa o processo de criação artística, Brito aproximou-se dos artistas nacionais cujas obras mais o atraíam, tais como Waltercio Caldas, Cildo Meireles, Iberê Camargo e Mira Schendel, e passou a conviver com eles, em uma experiência que chama de laboratório. Um dos primeiros críticos do país abordar em textos de catálogo a criação e a poética dos artistas, Brito adotou para si a postura ética de não escrever no Opinião sobre aqueles para os quais tivesse redigido um texto contratado. O envolvimento com artistas também teve como reflexo a participação na revista de arte Malasartes, em 1975 e 1976, e o jornal $A$ parte do fogo, no início da década de 80. Pouco depois, passou a dedicar-se à pesquisa acadêmica e à atuação como curador e escritor de livros de arte - e, conseqüentemente, afastou-se dos jornais.

Contemporâneo de Brito, o crítico Frederico Morais desenvolveu uma carreira crítica em múltiplas frentes. Trabalhou simultaneamente com produção de textos, organização de exposições, gerenciamento de museus dirigiu por 10 anos o Museu de Arte Moderna do Rio de Janeiro MAM-RJ; e ensino de história da arte. Ainda nos anos 60, foi titular da coluna de artes plásticas do Diário de Notícias, porém sua produção crítica mais célebre é a como responsável pela coluna "Artes plásticas" do jornal O Globo, de 1975 a 1987.

A coluna "Artes plásticas" não era publicada com periodicidade definida, mas, na segunda metade da década de 70, era incluída no Segundo Caderno de $O$ Globo de três a cinco vezes por semana, por vezes com foto freqüência que foi gradualmente caindo com o passar da década de 80. Os temas tratados na coluna variavam de acordo com o dia da semana. Aos domingos, Morais transformava-a em uma coleção de notas sobre aberturas de exposição em galerias e espaços públicos cariocas, uma agenda de arte comentada. Em meio aos tópicos, acrescentava notas de tom próximo ao de uma coluna social, mencionando o reconhecimento de artistas brasileiros 
no exterior e a passagem pelo país de autoridades ligadas à arte, como diplomatas. Caso os assessores de imprensa das galerias não lhe enviassem a tempo o texto de divulgação do artista, publicava sua reclamação.

Nos outros dias da semana, comentava uma exposição ou artista em particular. Morais não se resumia às mostras de arte contemporânea, comentando também as de arte popular, fotografia, design e moda. Intitulando-se "o colunista", adotava uma escrita livre, mas não totalmente informal. Quando redigia a análise de uma exposição ou trabalho de arte, elencava antes uma série de dados biográficos do artista em questão, procurando prover subsídios para que o interlocutor se familiarizasse com o assunto. Seus textos, especialmente os da década de 80 , oscilavam entre a crítica de arte e a crônica pessoal. Frederico Morais deixou a coluna em $O$ Globo em 1987, dedicando-se à curadoria e à pesquisa.

\section{A coluna Exposição coletiva}

Em novembro de 2004, o único crítico em atividade regular era Luiz Camillo Osório, no jornal O Globo, autor de três a quatro textos por mês no Segundo Caderno do periódico. Em novembro daquele ano, entretanto, o Jornal do Brasil anunciou o início da publicação no Caderno $B$ da coluna Exposição coletiva, a oito mãos. Eram elas: o arquiteto e diretor do Paço Imperial Lauro Cavalcanti; o curador do Museu de Arte Moderna do Rio de Janeiro, Fernando Cocchiarale; o designer e escritor Rafael Cardoso Denis; e a crítica de arte e curadora independente Marisa Flórido César. Em um sistema de rodízio, cada um deles ocupava o espaço a cada terça-feira, escrevendo na verdade uma vez por mês.

Logo no primeiro parágrafo do texto de inauguração da coluna, Lauro Cavalcanti definiu o perfil do leitor para o qual os quatro críticos se voltariam. "Alguns amigos consomem músicas e livros sofisticados, devoram filmes de arte e, no entanto, estão desinformados no que toca às artes visuais. As paredes de suas casas exibem obras sem qualidade ou reproduções de trabalhos antigos." "7 Ou seja, o interlocutor é das classes A e B, mas cujo cotidiano dificultaria uma aproximação das artes plásticas. Cavalcanti pressupôs um leitor leigo em arte dos séculos XX e XXI, ao qual o crítico deve orientar.

7 Cavalcanti, Lauro. "A distância entre a arte e o público". In Jornal do Brasil, 9 de novembro de 2004. Reprodução nos anexos. 
Os quatro críticos se reuniam todo mês para discutir os assuntos de cada coluna, mas dispunham de autonomia para escrever seus artigos. Fugindo ao modelo adotado pelas críticas de arte em jornais dos anos 90 e 2000, eles decidiram tratar não apenas de exposições, mas também fazer balanços do mercado de arte e da performance de artistas brasileiros no exterior, como se pode perceber pelos assuntos dos artigos publicados.

Cada crítico apresentou um estilo de escrita característico. Lauro Cavalcanti oscilava entre avaliações e resenhas - nas quais, em vez de avaliar, preferia esmiuçar o trabalho do artista cuja exposição era apresentada. Marisa Flórido, dos quatro, foi a que menos abriu mão de uma linguagem próxima à dos catálogos e artigos acadêmicos de arte: em artigos plenos de metáforas e poesia, vislumbrava as questões filosóficas por trás da obra. Fernando Cocchiarale dividiu-se entre a análise de exposições e artistas e a do momento cultural do país. Os artigos de Rafael Cardoso Denis procuram ser um constante convite ao leitor para que conheça a produção artística, em um texto claramente voltado para um interlocutor pressuposto sem qualquer contato com arte, prestes a iniciá-lo quase do zero.

O fato que ocasionou o fim de Exposição coletiva, em abril de 2005, não foi relacionado à coluna em si, mas sim um ato de adesão em decorrência da demissão do diretor de redação Marcus Barros Pinto, o qual havia convidado o quarteto para escrever no JB. Uma tentativa fugaz, porém enriquecedora enquanto esteve em andamento, a coluna apontou um caminho para a reintrodução da crítica de arte no noticiário impresso.

\section{Um novo caminho}

Em um período de 50 anos, a produção de jornais consolidou seu processo de industrialização baseado no princípio da objetividade. O meio artístico, por sua vez, acompanhou o fenômeno mundial de profissionalização das galerias e do mercado, com a consolidação de um circuito internacional de arte, e passou a ambicionar o reconhecimento no exterior. O embate da arte não é mais com a crítica, mas com o mercado.

Sem encontrar nos jornais a segurança financeira e o espaço reflexivo de outros tempos, os críticos de arte deram início à migração para campos nos quais seu trabalho obtivesse maior reconhecimento - processo que também ocorreu em outras esferas de atividade crítica, como a literária. A produção teórica e a pesquisa ganharam impulso, com a realização de estudos a médio e longo prazo amparados pelas universidades. Tais 
mudanças refletiram-se inclusive no estilo de escrita e formação dos profissionais da área, passando-se a uma predominância de análises baseados em estudos teóricos avançados, como uma forte presença de especialistas com formação universitária especializada. É importante salientar que, salvo exceções, tais críticos dirigem os textos produzidos na universidade a seus pares no meio acadêmico e não a um público leigo.

A curadoria de exposições foi outro ramo que atraiu um grupo de críticos cansado da batalha por espaço em jornais, como comprovam as biografias de Ronaldo Brito e Frederico Morais. Segundo Fernando Cocchiarale, "Em relação à nova arte, o curador deve, pois, produzir questões, quase sempre extra-estéticas, temáticas, que emprestem sentido, ainda que provisório, à dispersão aparente em que nos encontramos." 8

O que se assiste, nos anos 2000, é a um movimento de retorno dos dois grupos. Ambos operam uma tentativa de reinserção nos jornais, a busca por uma linguagem contemporânea para apresentar as artes visuais a um leitor não habituado. A coluna Exposição coletiva reuniu quatro críticos formados na academia, dois deles responsáveis pela curadoria de museus e centros culturais (Fernando Cocchiarale e Lauro Cavalcanti).

Mesmo com o desafio da baixa qualidade dos cadernos culturais, a crítica de arte se esforça para retomar o campo de troca com um público mais amplo. Particularidades como o discurso mais leve que o dos artigos acadêmicos e o revezamento de autores, em prol da diversidade de pontos de vista, podem ser a chave para a adaptação do texto crítico a um novo contexto de informação, com exigências de dinamismo e objetividade. Terminada por motivos alheios à sua produção, Exposição coletiva abriu a porta, por meio de seu modelo inédito no Brasil, a outras iniciativas do gênero.

O momento, portanto, é de otimismo. Em vez do fim, esta década pode estar assistindo ao recomeço desse debate crítico no meio impresso. Tal suposição só poderá ser verificada com a distância do tempo, mas não faltam indícios de que está para ocorrer.

8 Cocchiarale, Fernando, "Crítica: a palavra em crise", in BASBAUM, Ricardo (org.). Arte contemporânea brasileira: texturas, diçcões, ficções, estratégias, pp. 380 e 381. 


\section{Bibliografia}

BAUDELAIRE, Charles. A modernidade de Baudelaire. / Apresentação de Teixeira Coelho; tradução Sueli Cassal. Rio de Janeiro: Paz e Terra, 1988.

BASBAUM, Ricardo (org.). Arte contemporânea brasileira: texturas, dicções, ficções, estratégias.

BRITO, Ronaldo. Experiência crítica. Ronaldo Brito, organização de Sueli de Lima. São Paulo: Cosac \& Naify, 2005.

DUQUE-ESTRADA, Luís Gonzaga. Impressões de um amador: textos esparsos de crítica (1882-1909). / Gonzaga Duque; organização Julio Castañon Guimarães, Vera Lins. - Belo Horizonte: Editora UFMG; Fundação Casa de Rui Barbosa, 2001.

GONÇALVES, Lisbeth Rebollo, e FABRIS, Annateresa (org.) Os lugares da crítica de arte. São Paulo: Imprensa Oficial, 2005.

MORAIS, Frederico. Crônicas de amor à arte. Rio de Janeiro: Editora Revan, 1995.

PEDROSA, Mário. Forma e percepção estética - textos escolbidos II. / Mário Pedrosa, organização Otília Beatriz Fiori Arantes. São Paulo: EDUSP, 1996.

PIZA, Daniel. Jornalismo cultural. São Paulo: Contexto, 2003.

SODRÉ, Nelson Werneck. História da imprensa no Brasil. / Nelson Werneck Sodré. - 3a ed. - São Paulo: Martins Fontes, 1983. 